\title{
Minimizing Heat Loss Rate in Kaolin Thermal Insulation Layer in the Range of 800 to $1000^{\circ} \mathrm{C}$
}

\author{
Ogunrinola Iyanuoluwa Enoch ${ }^{a^{*}, \text { Akinyemi Marvel Lola }}{ }^{a}$, Ndubuisi Amanda ${ }^{a}$, Boyo Henry ${ }^{b}$, \\ Emetere Moses ${ }^{a}$, Inegbenebor Anthony ${ }^{b}$, and Aizebeokhai Ahzegbobor Philips ${ }^{a}$. \\ ${ }^{a}$ P.M.B 1023, Department of Physics, College of Science and Technology, Covenant University, Ota, Ogun State, Nigeria. \\ ${ }^{b}$ P.M.B 1023, Department of Mechanical Engineering, College of Engineering, Covenant University, Ota, Ogun State, Nigeria.
}

*ORCID: 0000-0002-7245-1965

\begin{abstract}
Storage of thermal energy has become a growing area of interest amongst researchers over the past few decades. This is so because of the wide variety of applications that can benefit from this technology. When perfected, waste heat from industrial plants and the sun can be stored for reuse at a later point in time, thus improving the energy efficiency of the system. Heat loss is a significant challenge that affects the efficiency of a thermal storage system especially at the high temperature range. In minimizing heat loss rate of thermal insulation layer, this work aims to use simulation models to determine and minimize rate of heat loss of a simulated cylindrical kaolin thermal insulator within the working temperature range of $800-1000{ }^{\circ} \mathrm{C}$. Two direction were used which are radial and axial. They were simulated and analyzed one after the other. Two simulation software were employed to validate the results from each of them. Length of thermal insulation, temperature of inner surface and ambient temperature were the independent variables accounted for this work while the rate of heat loss at the outer surface was the dependent variable. In the axial direction, the dependent variable was more sensitive to changes in the independent variables compared to the radial direction. The change in the length of the thermal insulation layer had the highest impact on the dependent variable followed by the temperature of the internal surface and then lastly by the combined effect of these two factors. The effect of ambient temperature was insignificant. From the results of the work, suggestion was made from the simulation results, that the length of $0.22 \mathrm{~m}$ will be used to construct a portable thermal storage unit within the operating temperature range of $700-900{ }^{\circ} \mathrm{C}$. In conclusion, results will also serve as framework for the simulation at higher working temperatures.
\end{abstract}

Keywords: Simulation, Thermal Insulator, Thermal storage, Heat loss, Kaolin, High temperature

\section{INTRODUCTION}

Construction of a thermal storage units is a multi-faceted endeavor which involves a combination of different subprojects. To ensure efficiency, proper optimization of significant parameters to the thermal storage unit is critical.
Over the years, researchers have employed both experimental and computational techniques to design and analyze thermal storage units. [1] simulate an optimization procedure for a fin based thermal storage unit. After selecting the factors that were significant, they carried out optimization using a multidimensional response surface method. [2] also made use the response surface methodology to optimize a thermal storage system by using variations of fin designs and the operating time of the system. It was concluded that the optimal fin design also varied with the operating time of the system. The experimental design to use depends on how the independent variables being considered influence the dependent variable. For instance, if the response show a linear trend, then a simple factorial design can be used. If on the other hand, a non-linear response is observed, the response surface methodology can be used. That helps researchers to have utilized optimization for finding out optimal parameters. [3] using the Taguchi and response surface method to minimize the burr height and surface roughness when drilling Al-7075, the cutting speed, feed rate and point angle parameters were the independent variables used in optimizing the desired response. Optimal values for these independent variables were obtained from their results. The choice of independent variables when designing a thermal storage unit depends on the factors which the researchers have found in literature and from experience to be significant to the response being investigated. [4] aimed at improving the charge and discharge performance of a thermal storage unit meant for solar energy and waste heat recovery. They did the experimental as well as the numerical simulation of the system then carried out optimization for the parameters they considered.

The thermal insulation is one of the most critical component of any thermal storage unit. This component to a very large extent determines how long the unit can hold the heat energy inside of it. For a material to be considered a good insulator, the thermal properties, the operating temperature of application and other significant factors must be put into consideration. It is always a good practice to put energy savings and cost into consideration when planning for the suitable thermal insulation to use ([5]; [6]; [7]). [8] worked on the simulating the critical radius of thickness of a ceramic thermal insulation crucible for high temperature application. The independent variables that were varies are the inner temperature, crucible thermal conductivity, 
convective heat transfer coefficient, thickness of the cylindrical crucible, ambient temperature and height of the cylindrical crucible. They found out that thermal conductivity had more effect on the rate of heat loss than the convective heat transfer coefficient. In this work, kaolin was considered as thermal insulator because of its properties. The simulation model was based on this.

Simulation of processes and systems have been carried out for years by researchers with the aim of having an idea about what the outcomes of a system will be without having to incur cost associated with experimentation ([9]; [10]; [11]; [2]; [12]; [13]; [14]; [1]; [8]). These simulations are useful as a guide in anticipation of possible challenges during experimentation. In this work, the simulation of the rate of heat loss at the outer surface of a portable cylindrical thermal insulating material is carried out. Afterwards, the rate of heat loss is minimized by adjusting significant parameters using a factorial design space.

\section{METHODOLOGY}

Numerical simulation was used to calculate the rate of heat loss at different thickness of thermal insulation in the radial and axial (crucible lid and bottom) direction given different internal temperatures for a unit length cylindrical thermal insulating crucible. One dimensional heat equation was used for the numerical simulation using the PDEPE (Partial Differential Equation Parabolic Elliptic) function in Matlab R2017a while the steady state thermal resistance equation was used for the simulation using Excel 2016. The simulation in Excel was done to validate the calculations done in Matlab.

\subsection{Design Parameters for the Simulation Model}

The PDEPE function in Matlab uses the one dimensional transient heat equation. In the axial direction, the simulation was modelled like a plane wall. Figure 1 shows the graphical representation of the simulation. $x_{0}$ is the internal surface while $x_{l}$ is the outer surface.

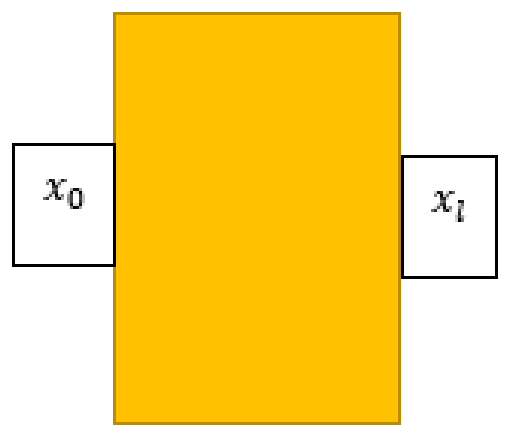

Figure 1: Axial direction modeled like a plane wall.

Equation 1a shows the one dimensional heat equation.

$$
\frac{\partial^{2} T(x, t)}{\partial x^{2}}=\frac{1}{\alpha} \frac{\partial T(x, t)}{\partial t}
$$

The generic boundary conditions for the simulated setup are:

$$
\begin{aligned}
& T\left(x_{0}, t\right)=T_{0} \\
& \dot{q}\left(x_{l}, t\right)=h\left(T_{l}-T_{a m b}\right)
\end{aligned}
$$

Initial condition is:

$$
T\left(x, t_{0}\right)=27{ }^{0} \mathrm{C}
$$

$T(x, t)$ is the temperature distribution in the axial direction $x$ at time $t, \alpha=k / \rho C_{p}$ is the thermal diffusivity, $k(0.3 \mathrm{~W} / \mathrm{m} \mathrm{K}$ in this case) is the thermal conductivity for Kaolin clay ([15]; [8]), $C_{p}=1223.67 \mathrm{~J} / \mathrm{kg} \mathrm{K}$ is the specific heat of kaolin clay [8], $\rho=$ $2600 \mathrm{~kg} / \mathrm{m}^{3}$ [16] is the density of Kaolin, $T_{0}$ is the temperature at the internal surface $x_{0}$ for all time $t, \dot{q}$ is the heat flux coming out from the external surface at $x_{l}, h$ is the convective heat transfer coefficient of whatever fluid surrounds the material (air in this case), $T_{l}$ is the temperature of outer surface at $x_{l}$ and $T_{a m b}$ is the temperature of the fluid around the outer surface or the ambient temperature.

The following assumptions were made:

I. Constant thermal conductivity of kaolin in space and with temperature is assumed

II. None turbulent air flow at the outer surface $(h=10$ $\mathrm{W} / \mathrm{m}^{2} \mathrm{~K}$ for none turbulent air)

III. No heat generation within the material that is between $x_{0}$ and $x_{l}$.

IV. The geometry of a plane wall is assumed for the axial direction.

For the radial direction, equation 2 a shows the heat equation for the cylinder

$$
\frac{1}{r} \frac{\partial}{\partial r}\left(r \frac{\partial T(r, t)}{\partial r}\right)=\frac{1}{\alpha} \frac{\partial T(r, t)}{\partial t}
$$

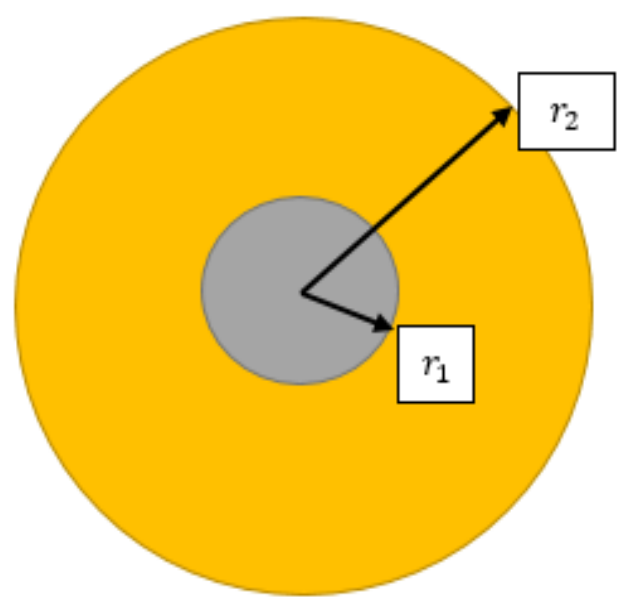

Figure 2: Radial direction showing the internal and external radii.

The boundary conditions for the radial direction are:

$$
T\left(r_{1}, t\right)=T_{1}
$$


International Journal of Engineering Research and Technology. ISSN 0974-3154, Volume 13, Number 11 (2020), pp. 3178-3188

(C) International Research Publication House. https://dx.doi.org/10.37624/IJERT/13.11.2020.3178-3188

$$
\dot{q}\left(r_{2}, t\right)=h\left(T_{2}-T_{a m b}\right)
$$

The initial condition is:

$$
T\left(r, t_{0}\right)=27{ }^{0} C
$$

$T(r, t)$ is the temperature distribution in the radial direction $r$ at time $t, \alpha=k / \rho C_{p}$ is the thermal diffusivity, $k$ is the thermal conductivity of Kaolin, $C_{p}$ is the specific heat capacity of Kaolin, $\rho$ is the density, $T_{1}$ is the temperature at the inner surface $r_{1}, \dot{q}$ is the heat flux coming out from the outer surface at $r_{2}, h$ is the convective heat transfer coefficient of air (assuming non turbulent flow), $T_{2}$ is the temperature of the outer surface at $r_{2}$ and $T_{a m b}$ is the ambient temperature.

The following assumptions were made:

I. Thermal conductivity is constant in space and with temperature

II. Air flow at the outer surface is non turbulent $(h=10$ $\mathrm{W} / \mathrm{m}^{2} \mathrm{~K}$ for none turbulent air)

III. No heat generation within the material that is between $r_{1}$ and $r_{2}$.

IV. The cylinder is of unit length.

After numerically computing $T_{l}$ in the axial direction and $T_{2}$ in the radial direction in Matlab, the thermal resistance equation for conduction and convection were used to compute the rate of heat loss at the outer surface in the axial direction at $x_{l}$ and at the outer surface in the radial direction at $r_{2}$.

\section{$2.2 \quad$ Using Excel 2016}

The steady state thermal resistance equation was used in Excel 2016 to validate the results from the PDEPE function which was run on Matlab R2017a. The thermal resistance equation was used to calculate the rate of heat loss at the outer surfaces in the axial and radial direction as well. The steady state thermal resistance equation was used for this approach. In the axial direction, the plane wall geometry approach was utilized. Equation $3 \mathrm{a}$ shows the general form of the thermal resistance equation.

$$
\dot{Q}=\frac{T_{1}-T_{a m b}}{R_{\text {cond }}+R_{\text {conv }}}
$$

For the axial direction, $R_{\text {cond }}$ which is thermal resistance to conduction is

$$
R_{\text {cond }}=\frac{x_{0}-x_{l}}{k A}
$$

$A=1$ in this case because:

I. Only the axial direction is being considered here and

II. The geometry in this case is being considered as a plane wall

$R_{\text {conv }}$ which is the thermal resistance to convection is given by Equation $3 \mathrm{c}$

$$
R_{\text {conv }}=1 / h A
$$

Again, $\mathrm{A}=1$.
For the radial direction,

$$
\begin{aligned}
& R_{\text {cond }}=\frac{\ln \left(r_{2} / r_{1}\right)}{2 \pi L k} \\
& R_{\text {conv }}=\frac{1}{h\left(2 \pi r_{2} L\right)}
\end{aligned}
$$

$L$ is the length of the cylinder and $L=1$ as stated in the assumptions.

Analytical computation for the axial and the radial directions on Excel resulted in exactly the same values for those computed numerically with the heat equation on Matlab.

\subsection{Optimization Procedure}

The main goal was to get the lowest rate of heat loss by varying different factors and observing the effects of varying the factors on the rate of heat loss. In order to achieve this, significant and insignificant factors were considered. Thereafter, the insignificant factors were ignored for focus to be on the significant factors. Some factors were varied while some other factors were kept constant.

In the axial direction, the following were varied in order to determine their various effects on the dependent variable:

I. The inner temperature $T_{0}$

II. Ambient temperature $T_{a m b}$ and

III. Axial length of the insulation layer $l=x_{l}-x_{0}$.

Whereas in the radial direction the following factors were varied:

I. Inner temperature $T_{1}$

II. Ambient temperature $T_{a m b}$, and

III. Radial length of the insulation layer.

The following are the values that were kept constant:

I. Thermal diffusivity of Kaolin (calculated from $\alpha=$ $k / \rho C_{p}$ to be $0.0000000943 \mathrm{~m}^{2} / \mathrm{s}$ )

II. $h=10 \mathrm{~W} / \mathrm{m}^{2} \mathrm{~K}$ is the convective thermal transfer coefficient of air (non-turbulent flow)

III. $\quad r_{1}$ for the radial direction was kept constant at $0.08 \mathrm{~m}$

The following are the values of the factors that were varied:

I. $\quad T_{0}$ for the axial direction was 800 and $1000{ }^{\circ} \mathrm{C}$

II. $\quad T_{1}$ for the radial direction was 800 and $1000{ }^{\circ} \mathrm{C}$

III. $T_{a m b}$ was 30 and $40{ }^{\circ} \mathrm{C}$

IV. $x_{l}-x_{0}=l$ which is the length of the insulating layer in the axial direction was 0.12 and $0.22 \mathrm{~m}$

V. $\quad r_{2}$ was 0.2 and $0.3 \mathrm{~m}$ making $r_{2}-r_{1}=0.12$ and 0.22 $\mathrm{m}$ as well.

With the information about the factors and their levels given, a $2^{3}$ factorial design was run using the Design Expert 10.0.4 software. A template consisting of experimental runs involving 
three factors and two levels of each factor was generated using the software. The three factors $T_{0}, T_{a m b}$ and $l$ were varied for the axial direction and the factors $T_{1}, T_{a m b}$ and $r_{2}$ were varied for the radial direction. The experimental runs were simulated numerically on Matlab and then validated analytically on Excel.

\section{RESULTS AND DISCUSSION}

The results of the simulation were inputted into the template generated by the Design Expert software for further analysis. The template shows different values/levels of the independent variables to be used and then provides a column for the resulting values of the dependent variable. After data was fed into the template, a "cause and effect" relationship between the independent variables and the dependent variable was established similar to what [17] and [18] did in their study.

\subsection{Results and Analysis for the Axial Direction}

The summary of the design space for the two factor and two level factorial design with the coded and real value is shown in Table 1. There were three independent variables and two levels for each of these variables making a total of eight (8) runs. The independent variables were $T_{0}, l$ and $T_{a m b}$ (represented in the Design Expert software by $A, B$ and $C$ respectively) which are the inner temperature, the length of the slab and the ambient temperature at the outer surface $x_{l}$. The dependent variable which is the rate of heat loss $\dot{Q}$ is represented by $R 1$ in the software. The range of values for the independent variables creates a navigable design space using the "cause and effect" relationship/regression equation. Predictions that exceed this range can be made but the accuracy is subject to the statistical R-predicted value of the regression equation or "cause and effect" relationship, that is, the R-predicted value must be sufficiently close to $100 \%$.

Figure 3 shows the magnitude of effect each independent variable has on the dependent variable after the result was filled into the template. The further to the right the independent variables are, the higher their effect on the dependent variable. The length of the slab has the highest influence followed by the temperature of the inner surface and then the interaction of the effect of these two independent variables represented by $A B$. Every other variable and interactions on or below the line are insignificant and can be ignored. It makes a lot of sense because the higher the length of the thermal insulation, the better it is at cutting down heat loss at the outer surface as observed by these authors ([15]; [8]). The temperature at the inner surface also has a significant effect. The ambient temperature does not really count here. Its effect is negligible [8].

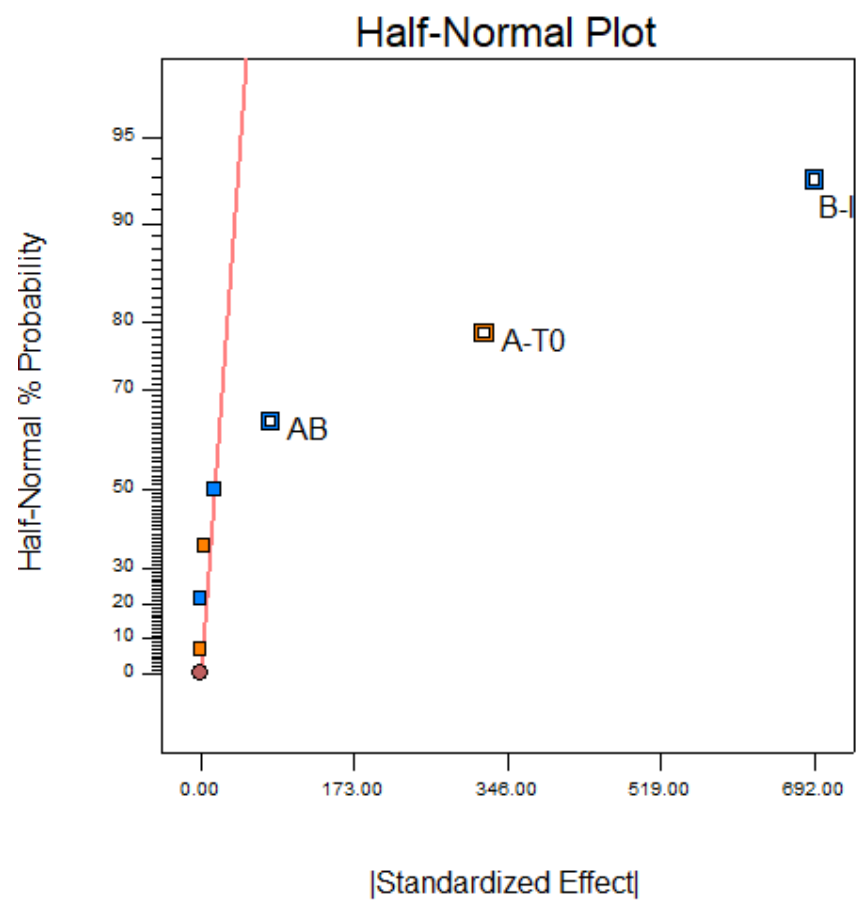

Figure 3: Half-Normal plot of effects

On the other hand, Figure 4 not only shows the magnitude of effect, it also shows how these effects influence the dependent variables. In other words, it shows both the magnitude and "direction" of these effects. For instance, effects on the righthand side beyond the line shows independent variables that significantly increase the dependent variable when increased and vice versa while the independent variables to the left beyond the line shows independent variables whose increase reduces the dependent variable and vice versa. The farther away they are from the line, the stronger their effects. From the result, increase in the temperature of the inner surface increased the rate of heat loss at the outer surface whereas increase in length of the thermal insulation layer reduced the rate of heat loss at the outer surface.

Table 1: Design summary of the factorial design

\begin{tabular}{|l|l|l|l|l|l|l|l|l|}
\hline Factor & Name & Units & Type & Subtype & Minimum & Maximum & \multicolumn{2}{l|}{ Coded Values } \\
\hline $\mathrm{A}$ & $\mathrm{T}_{0}$ & ${ }^{0} \mathrm{C}$ & Numeric & Continuous & 800 & 1000 & $-1=800$ & $+1=1000$ \\
\hline $\mathrm{B}$ & 1 & $\mathrm{~m}$ & Numeric & Continuous & 0.12 & 0.22 & $-1=0.12$ & $+1=0.22$ \\
\hline C & $\mathrm{T}_{\mathrm{amb}}$ & ${ }^{0} \mathrm{C}$ & Numeric & Continuous & 30 & 40 & $-1=30$ & $+1=40$ \\
\hline Response & Name & Units & Observations & Analysis & Minimum & Maximum & & \\
\hline R1 & $\dot{Q}$ & $\mathrm{~W}$ & 8 & Factorial & 912 & 1940 & & \\
\hline
\end{tabular}


Another way to show the significance of factors is by using the Pareto chart. This chart is similar to the Normal plot but the level of significance is the t-value limit or the Bonferroni limit. As shown in Figure 5, the significant factors are above these limits. Again from Figure 5, we have the length of insulating material, internal temperature and the interaction between these two to be significant.

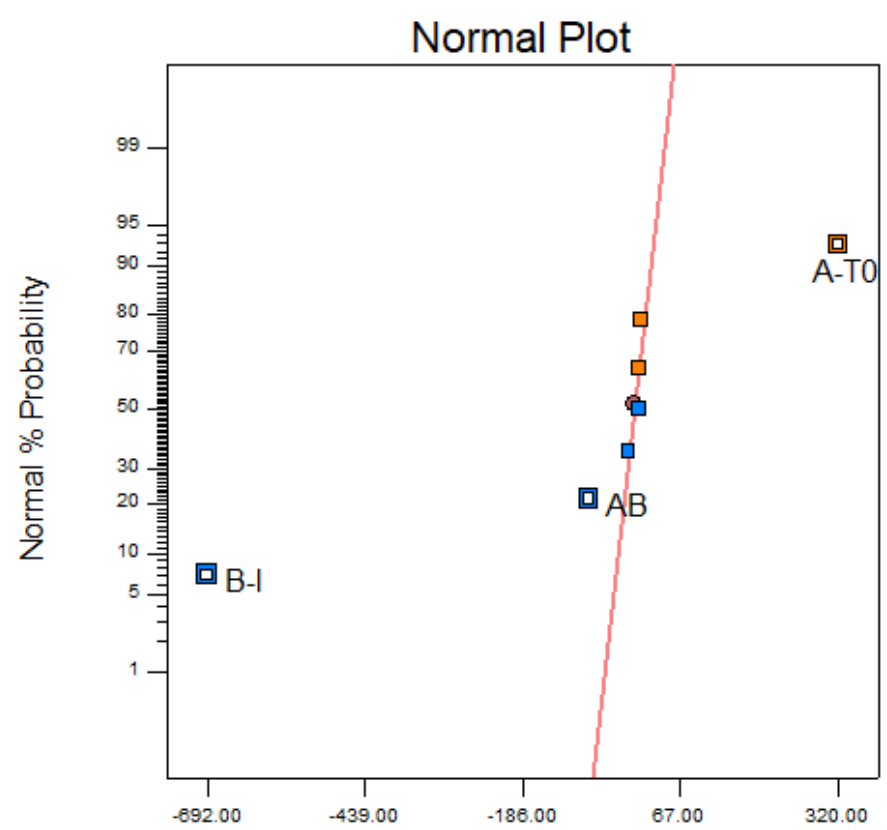

Standardized Effect

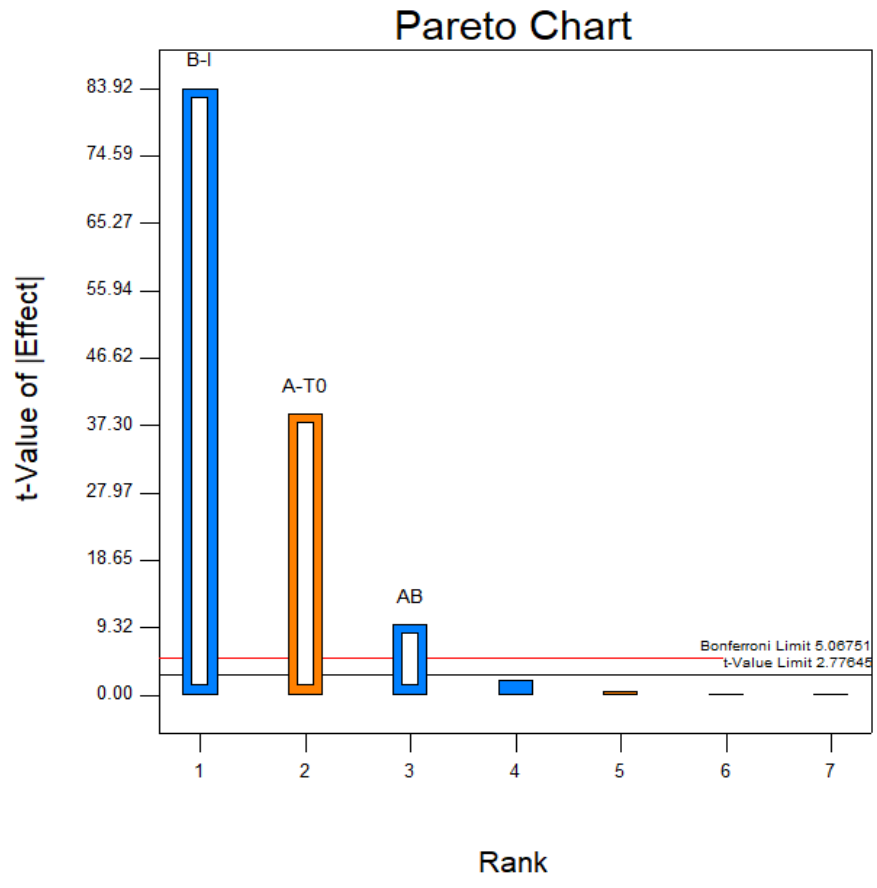

Figure 5: Pareto chart showing significant and insignificant effects of factors

In order to mathematically determine the relationship between the independent variables with the dependent variables, regression analysis was run including only the significant independent variables.

Figure 4: Full-Normal plot of effects

Table 2: Analysis of variance (ANOVA) table for the factorial model for the axial direction

\begin{tabular}{|l|c|c|c|c|c|c|}
\hline \multicolumn{1}{|c|}{ Source } & $\begin{array}{c}\text { Sum of } \\
\text { Squares }\end{array}$ & $\begin{array}{c}\text { Degrees of } \\
\text { Freedom }\end{array}$ & $\begin{array}{c}\text { Mean } \\
\text { Square }\end{array}$ & F Value & $\begin{array}{c}\text { P-value } \\
\text { Prob>F }\end{array}$ & $<0.0001$ \\
\hline Model & $1.175 \mathrm{E}+06$ & 3 & $3.918 \mathrm{E}+05$ & 2880.71 & significant \\
\hline A-T $\mathrm{T}_{0}$ & $2.048 \mathrm{E}+05$ & 1 & $2.048 \mathrm{E}+05$ & 1505.88 & $<0.0001$ & $<0.0001$ \\
\hline B-1 & $9.577 \mathrm{E}+05$ & 1 & $9.577 \mathrm{E}+05$ & 7042.12 & 0.0006 & \\
\hline AB & 12800 & 1 & 12800 & 94.12 & & \\
\hline Residual & 544 & 4 & 136 & & & \\
\hline Total & $1.176 \mathrm{E}+06$ & 7 & & & & \\
\hline R-Squared & 0.9995 & & & & & \\
\hline Adj R-Squared & 0.9992 & & & & & \\
\hline Pred. R-Square & 0.9981 & & & & & \\
\hline
\end{tabular}

Table 2 shows the analysis of variance (ANOVA) table for the factorial model. For an alpha level of 0.05 or a confidence level of $95 \%$, the model is significant. The variation of the dependent variable is well explained by the independent variables. The most variation of the rate of heat loss is explained by the length of the thermal insulating material, followed by the temperature of the inner surface then last by the interaction effect of these first two variables. The R-squared vales tells us the percentage of the variation in the dependent variable that is explained by the independent variables. In this case, the independent variables explains $99.95 \%$ of the variation of the rate of heat loss. The R-squared adjusted is the R-squared value adjusted 
for the number of independent variables being considered. The R-squared predicted tells us how well this model will be able to accurately predict values outside of the design space

The final equation in terms of coded factors:

$$
\dot{Q}=1384+160 * A-346 * B-40 * A * B
$$

The equation in terms of coded factors can be used to make predictions about the response for given levels of each factor. By default, the high levels of the factors are coded as +1 and the low levels of the factors are coded as -1 . The coded equation is useful for identifying the relative impact of the factors by comparing the factor coefficients. When there is a unit increase in $A$ with every other independent variable kept constant, the dependent variable $\dot{Q}$ increases by $160 \mathrm{~W}$. likewise when there is a unit increase in the length of the slab $B$ when other variables are kept constant, then $\dot{Q}$ reduces by $346 \mathrm{~W}$ and lastly, when there is a unit increase in the interaction $A * B$ when the other variables are kept constant, there is a decrease in $\dot{Q}$ by $40 \mathrm{~W}$. The final equation in terms of the actual factors is:

$$
\dot{Q}=-103.6+2.96 * T_{0}+280 * l-8 * T_{0} l
$$

The equation in terms of actual factors can be used to make predictions about the response for given levels of each factor. Here, the levels should be specified in the original units for each factor.

The rate of heat loss as a function of the length of the thermal insulator and the internal temperature is shown in Figure 6. The most desirable part of the plot is the top-left region. This region is where the rate of heat loss is at the minimum. This of course comes with a consequence of increased length of thermal insulating material resulting in increased cost and size of the thermal storage system. On the other hand, the lower right corner of the plot is the region to avoid. It shows the region where heat loss is highest.

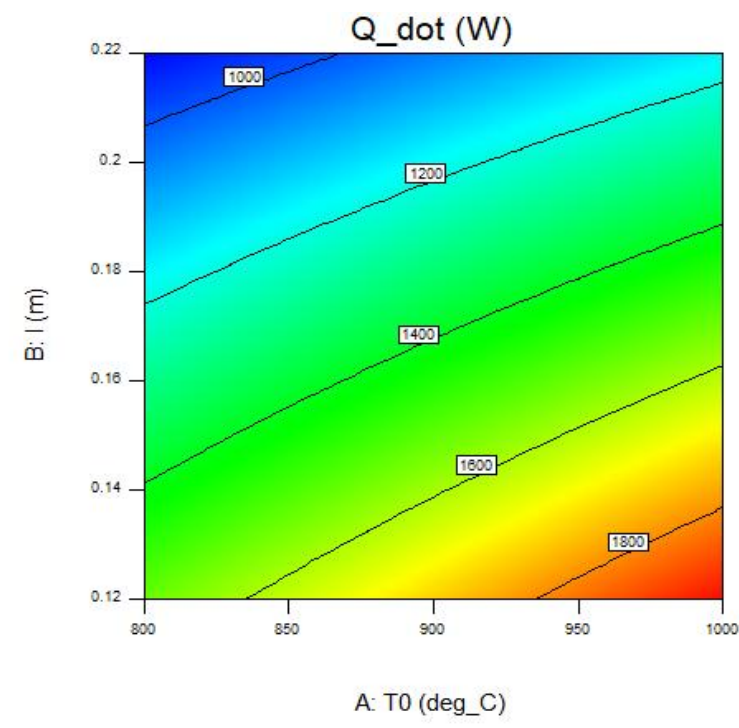

Figure 6: Contour plot of rate of heat loss as influenced by temperature of internal surface and length of thermal insulating material
Another way to gain insight into the variation of the heat loss rate is to visualize a three dimensional plot. Figure 7 shows such kind of plot.

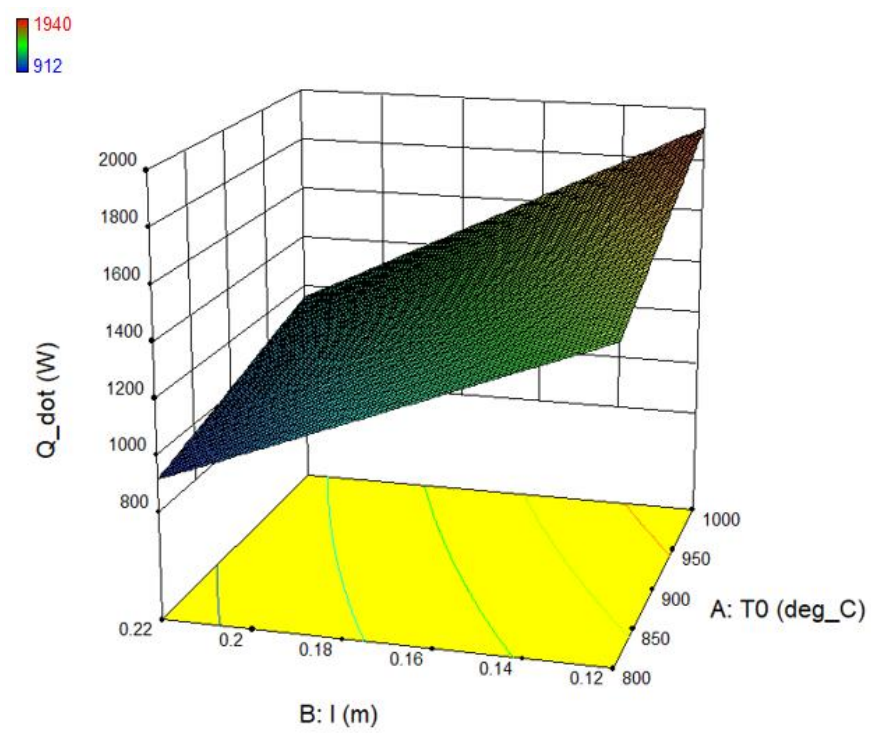

Figure 7: 3-D plot of rate of heat loss as influenced by temperature of internal surface and length of thermal insulating material

\subsection{Optimized Values for the Variables - Axial Direction}

After careful observation of Figure 7, the software was programmed to find solutions showing the most desirable values of the response variable. The goal was to minimize the following in order of priority:

I. Minimize the rate of heat loss at the outer surface

II. Minimize the length of thermal insulation to achieve this reduction

Several solutions were presented but only two were chosen because they gave solutions representing two extremes for the temperature of the internal surface and the corresponding values of other variables. Table 3 shows the rate of heat loss if the optimized values presented for the independent variables are used.

Table 3: Values for the first chosen solution

\begin{tabular}{|l|l|l|l|l|}
\hline Factor & Name & Level & $\begin{array}{l}\text { Low } \\
\text { Level }\end{array}$ & $\begin{array}{l}\text { High } \\
\text { Level }\end{array}$ \\
\hline $\mathrm{A}$ & $\mathrm{T}_{0}$ & 800 & 800 & 1000 \\
\hline $\mathrm{B}$ & 1 & 0.22 & 0.12 & 0.22 \\
\hline $\mathrm{C}$ & $\mathrm{T}_{\mathrm{amb}}$ & 40 & 30 & 40 \\
\hline Response & Mean & \multicolumn{4}{|l}{} \\
\hline$\dot{Q}$ & 918 & & \\
\hline
\end{tabular}


Figure 8 shows the point corresponding to the optimized value of the dependent variable on a three dimensional plot given that the temperature for the inner surface is $800^{\circ} \mathrm{C}$ and the length of the thermal insulating layer is $0.22 \mathrm{~m}$.

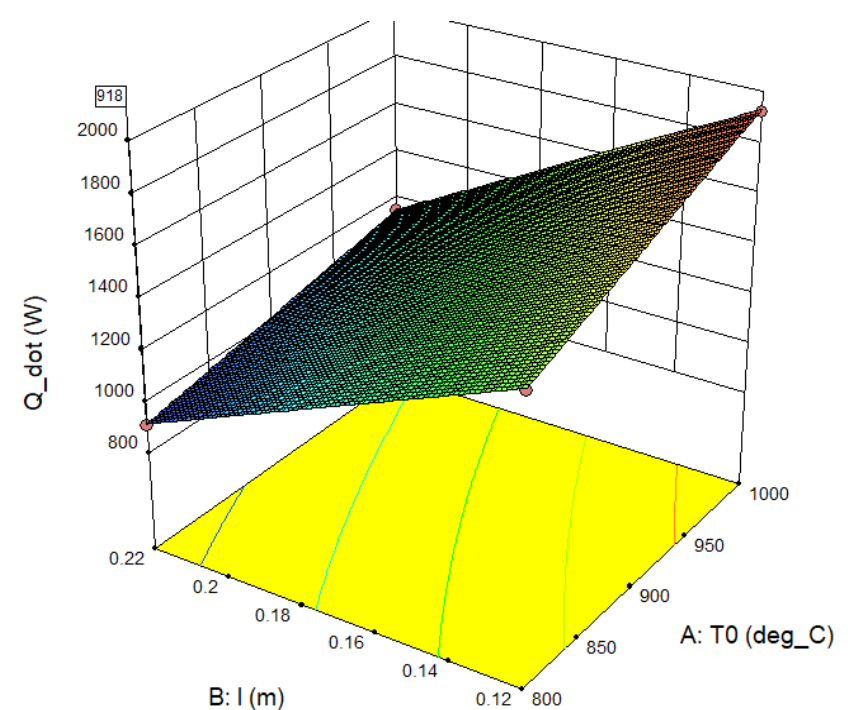

Figure 8: Optimal point for first chosen solution

For the second chosen solution, Table 4 shows the optimized parameters and resulting response. Here, for temperatures that are close to the upper end of the range, the rate of heat loss is higher. The remedy for this is increasing the length of the thermal insulation layer but this comes at a cost of overall size and finance which is part of what is being minimized.

Table 4: Values for the second chosen solution

\begin{tabular}{|l|l|l|l|l|}
\hline Factor & Name & Level & $\begin{array}{l}\text { Low } \\
\text { Level }\end{array}$ & $\begin{array}{l}\text { High } \\
\text { Level }\end{array}$ \\
\hline $\mathrm{A}$ & $\mathrm{T}_{0}$ & 977.20 & 800 & 1000 \\
\hline $\mathrm{B}$ & 1 & 0.22 & 0.12 & 0.22 \\
\hline $\mathrm{C}$ & $\mathrm{T}_{\mathrm{amb}}$ & 30 & 30 & 40 \\
\hline Response & Mean & \multicolumn{4}{|l}{} \\
\cline { 1 - 2 }$\dot{Q}$ & 1130.64 & \multicolumn{3}{|l}{} \\
\cline { 1 - 2 } & & &
\end{tabular}

In Figure 9, the three dimensional plot where the optimized response value is identified for the second chosen solution is displayed for visual clarity.
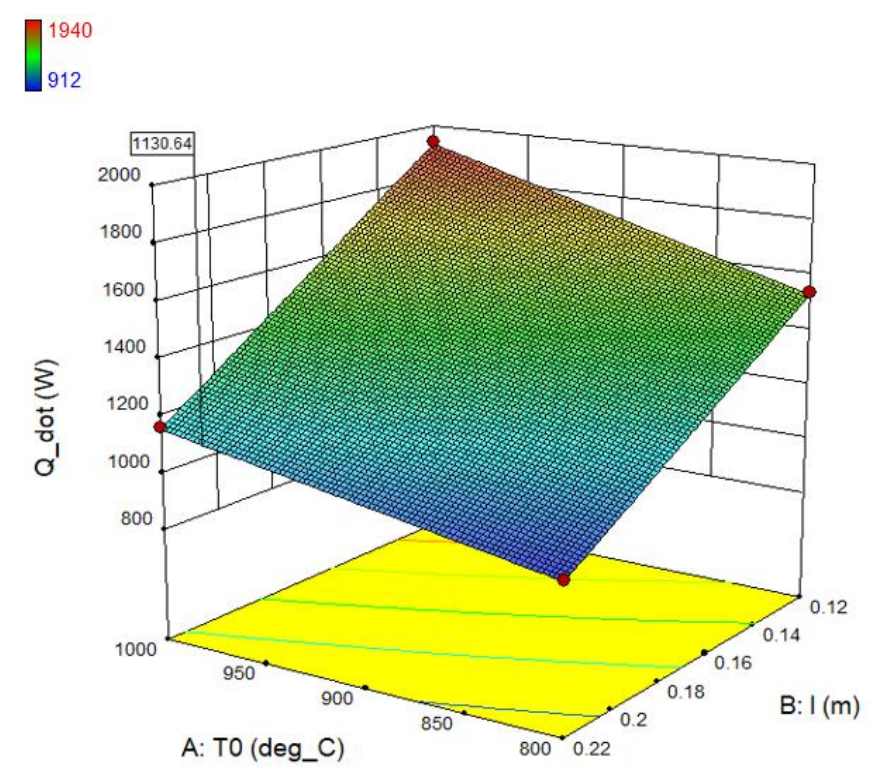

Figure 9: Optimal point for second chosen solution

\subsection{Results and Analysis for the Radial Direction}

The summary of the design space for the two factor and two level factorial design is shown in Table 5. There were three independent variables and two levels for each of these variables making a total of eight (8) runs. The independent variables were $T_{1}, r_{2}$ and $T_{\infty}$ (represented in the Design Expert software by $A, B$ and $C$ respectively) which are the inner temperature, the outer radius of the cylinder and the ambient temperature at the outer surface of the cylinder. The dependent variable which is the rate of heat loss $\dot{Q}$ is represented by $R 1$ in the software.

Figure 10 shows the magnitude of effect each independent variable has on the dependent variable. The further to the right the independent variables are, the higher their effect on the dependent variable. The radial length of the cylinder has the highest influence followed by the temperature of the inner surface and then the interaction of the effect of these two independent variables represented by $A B$. Every other variable and interactions on or below the line are insignificant and can be ignored. The temperature at the inner surface also has a significant effect. Again, the ambient temperature does not really count here [8].

Table 5: Design summary of the factorial design

\begin{tabular}{|l|l|l|l|l|l|l|l|l|}
\hline Factor & Name & Units & Type & Subtype & Minimum & Maximum & \multicolumn{2}{l|}{ Coded Values } \\
\hline A & $\mathrm{T}_{1}$ & ${ }^{0} \mathrm{C}$ & Numeric & Continuous & 800 & 1000 & $-1=800$ & $+1=1000$ \\
\hline $\mathrm{B}$ & $\mathrm{r}_{2}$ & $\mathrm{~m}$ & Numeric & Continuous & 0.2 & 0.3 & $-1=0.12$ & $+1=0.22$ \\
\hline $\mathrm{C}$ & $\mathrm{T}_{\mathrm{amb}}$ & ${ }^{0} \mathrm{C}$ & Numeric & Continuous & 30 & 40 & $-1=30$ & $+1=40$ \\
\hline Response & Name & Units & Observations & Analysis & Minimum & Maximum & & \\
\hline R1 & $\dot{Q}$ & $\mathrm{~W}$ & 8 & Factorial & 1007.6 & 1714.74 & \\
\hline
\end{tabular}




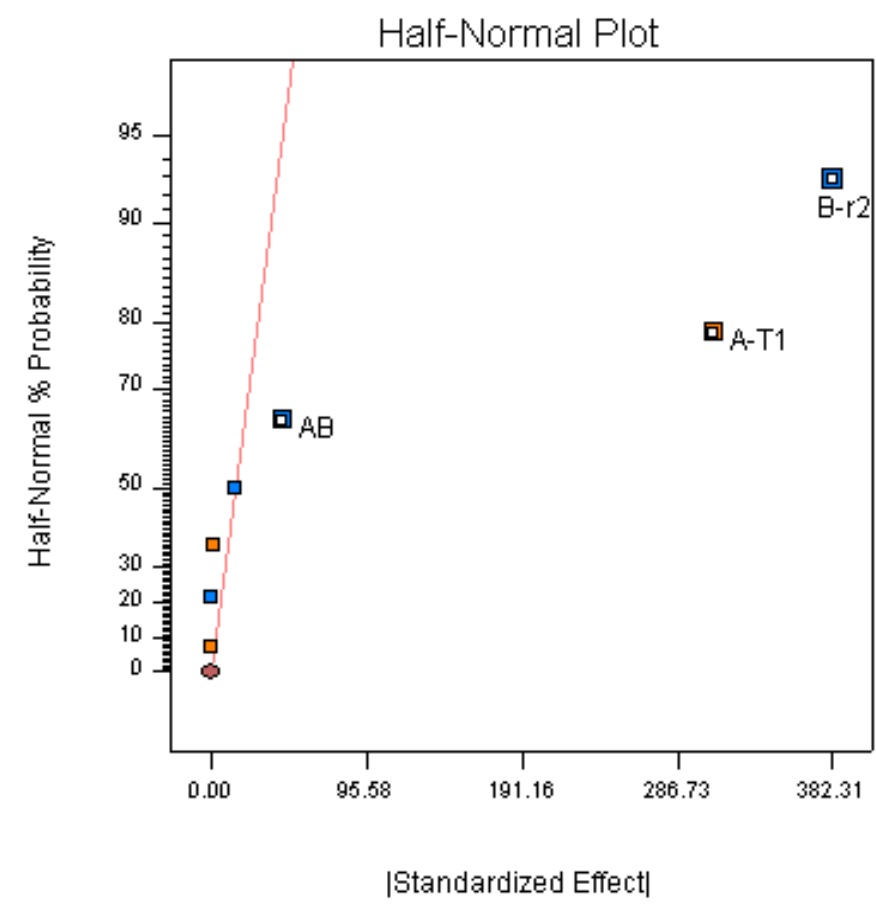

Figure 10: Half-Normal plot of effects

Similar to Figure 4, Figure 11 not only shows the magnitude of effect, it also shows how these effects influence the dependent variables. From the result, increase in the temperature of the inner surface increased the rate of heat loss at the outer surface whereas increase in length of the thermal insulation layer reduced the rate of heat loss at the outer surface. Compared to

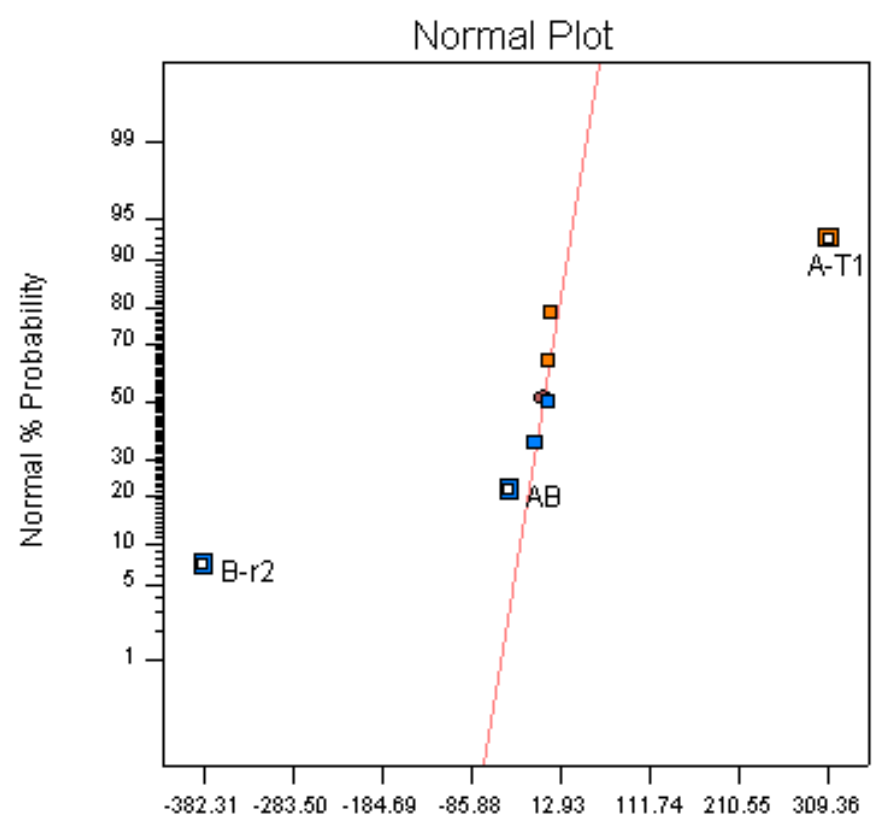

Standardized Effect

Figure 11: Full-Normal plot of effects
Figure 4, the magnitude of effect for the independent variables is higher in the axial direction. In other words, there is a higher sensitivity to change of any of the independent variables on the dependent variable. This might be due to the geometric difference in both situations.

Again from Figure 12, we have the radial length of insulating material, temperature of the internal surface and the interaction between these two to be significant. It can also be seen here that the overall magnitude of effect is lower compared to the axial direction.

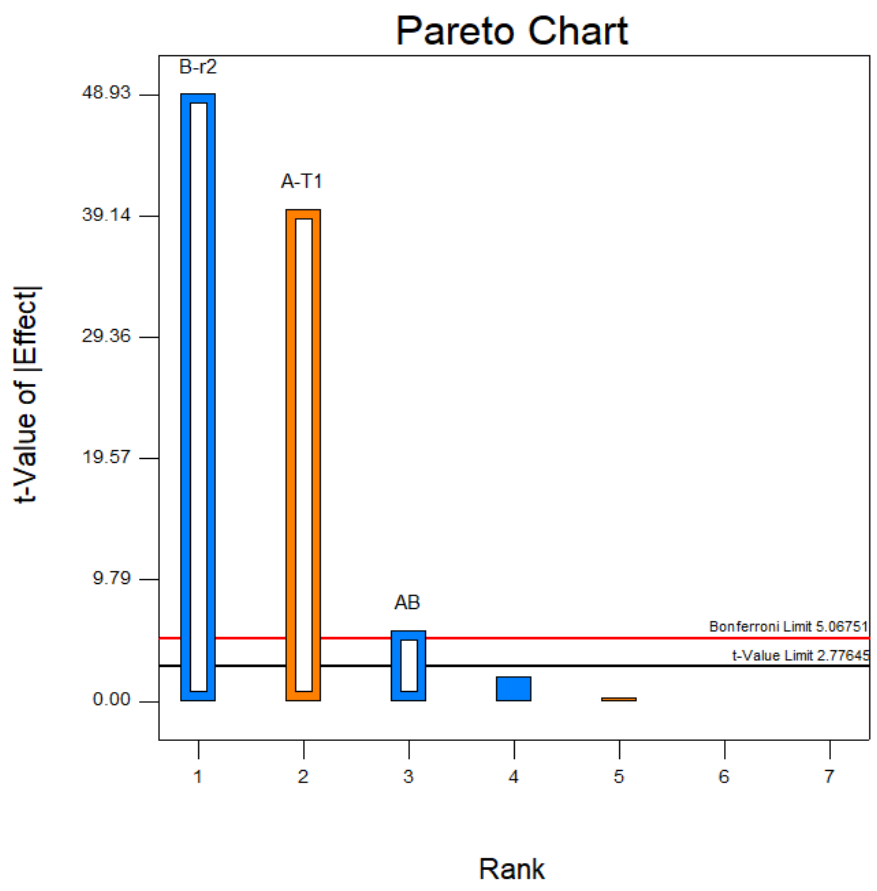

Figure 12: Pareto chart showing significant and insignificant effects of factors

In order to mathematically determine the relationship between the independent variables with the dependent variables just like what was done for the case of the axial direction, regression analysis was run including only the significant independent variables. Table 6 shows the ANOVA table for the factorial model. Again, for an alpha level of 0.05 , the model is significant. The variation of the dependent variable is well explained by the independent variables. Similar to the case in Table 2, the most variation of the rate of heat loss is explained by the radial length of the thermal insulating material, followed by the temperature of the inner surface then last by the interaction effect of these first two variables. For the R-squared value, the independent variables explains $99.99 \%$ of the variation of the rate of heat loss. 
International Journal of Engineering Research and Technology. ISSN 0974-3154, Volume 13, Number 11 (2020), pp. $3178-3188$

(C) International Research Publication House. https://dx.doi.org/10.37624/IJERT/13.11.2020.3178-3188

Table 6: Analysis of variance (ANOVA) table for the factorial model for the radial direction

\begin{tabular}{|l|l|l|l|l|l|l|}
\hline Source & $\begin{array}{l}\text { Sum of } \\
\text { Squares }\end{array}$ & $\begin{array}{l}\text { Degrees of } \\
\text { Freedom }\end{array}$ & Mean Square & F Value & $\begin{array}{l}\text { P-value } \\
\text { Prob>F }\end{array}$ & \\
\hline Model & $4.876 \mathrm{E}+05$ & 3 & $1.625 \mathrm{E}+05$ & 1331.22 & $<0.0001$ & significant \\
\hline A-T 1 & $1.914 \mathrm{E}+05$ & 1 & $1.914 \mathrm{E}+05$ & 1567.59 & $<0.0001$ & \\
\hline B-r 2 & $2.923 \mathrm{E}+05$ & 1 & $2.923 \mathrm{E}+05$ & 2394.07 & $<0.0001$ & \\
\hline AB & 3907.28 & 1 & 3907.28 & 32 & 0.0048 & \\
\hline Residual & 488.41 & 4 & 122.10 & & & \\
\hline Total & $4.881 \mathrm{E}+05$ & 7 & & & & \\
\hline R-Squared & 0.9990 & & & & & \\
\hline Adj R-Squared & 0.9982 & & & & & \\
\hline Pred. R-Square & 0.9960 & & & & & \\
\hline
\end{tabular}

The final equation in terms of coded factors:

$$
\dot{Q}=1337.97+154.68 * A-191.16 * B-22.1 * A * B
$$

Again, by default, the high levels of the factors are coded as +1 and the low levels of the factors are coded as -1 . When there is a unit increase in $A$ with every other independent variable kept constant, the dependent variable $\dot{Q}$ increases by $154.68 \mathrm{~W}$. likewise when there is a unit increase in the radial length of the cylinder $B$ when other variables are kept constant, then $\dot{Q}$ reduces by $191.16 \mathrm{~W}$ and lastly, when there is a unit increase in the interaction $A * B$ when the other variables are kept constant, there is a decrease in $\dot{Q}$ by $22.1 \mathrm{~W}$. The final equation in terms of the actual factors is:

$$
\dot{Q}=-92.88+2.6518 * T_{1}+154.9 * r_{2}-4.42 * T_{1} * r_{2}
$$

The equation in terms of actual factors can be used to make predictions about the response for given levels of each factor. Here, the levels should be specified in the original units for each factor. The rate of heat loss as a function of the length of the thermal insulator and the internal temperature is shown in Figure 13. Similar to Figure 6, the most desirable part of the plot is the top-left region. This region is where the rate of heat loss is at the minimum. On the other hand, the lower right corner of the plot is quite the opposite.

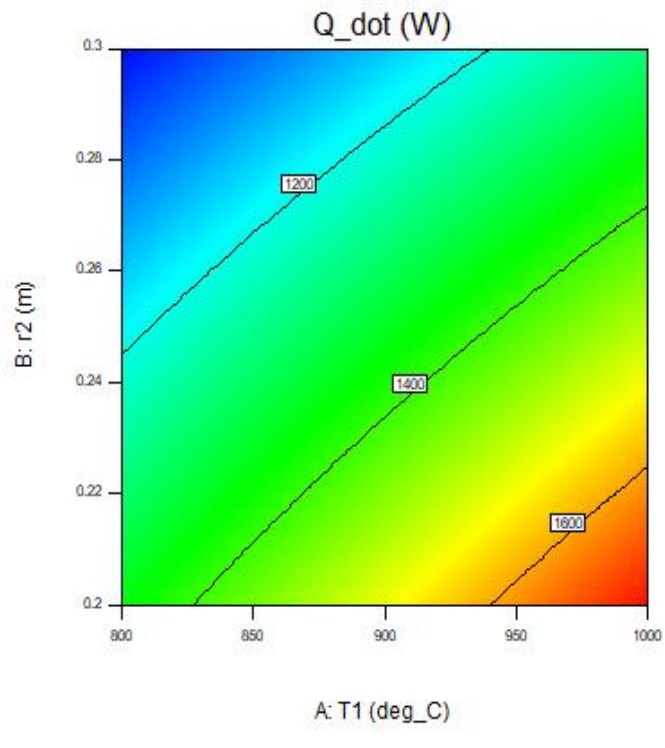

Figure 13: Contour plot of rate of heat loss as influenced by temperature of internal surface and radial length of thermal insulating material

Gaining more insight into the variation of the rate of heat loss can be done by visualizing a three dimensional plot. Figure 14 shows such kind of plot. 
\1007.6

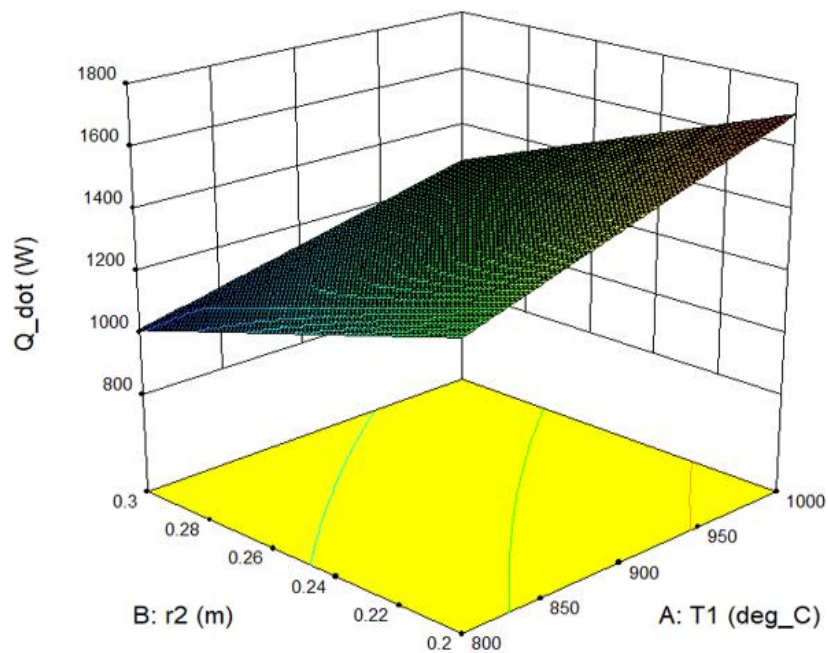

Figure 14: Three dimensional plot of rate of heat loss as influenced by temperature of internal surface and radial length of thermal insulating material

\subsection{Optimized Values for the Variables - Radial Direction}

After careful observation of Figure 14, the software was programmed to find solutions showing the most desirable values of the response variable with the goal of minimizing the rate of heat loss at the outer surface as well as minimizing the length of insulation needed for this. The following was the result of the optimization process. Table 7 shows the rate of heat loss if the optimized values presented for the independent variables are used.

Table 7: Optimized Values for the Variables

\begin{tabular}{|c|c|c|c|c|}
\hline Factor & Name & Level & $\begin{array}{l}\text { Low } \\
\text { Level }\end{array}$ & $\begin{array}{l}\text { High } \\
\text { Level }\end{array}$ \\
\hline A & $\mathrm{T}_{1}$ & 800 & 800 & 1000 \\
\hline B & $\mathrm{r}_{2}$ & 0.30 & 0.20 & 0.30 \\
\hline $\mathrm{C}$ & $\mathrm{T}_{\mathrm{amb}}$ & 40 & 30 & 40 \\
\hline Response & Mean & & & \\
\hline$\dot{Q}$ & 1014.23 & & & \\
\hline
\end{tabular}

Figure 15 shows the point corresponding to the optimized value of the dependent variable on a three dimensional plot given that the temperature for the inner surface is $800^{\circ} \mathrm{C}$ and the radial length of the thermal insulating layer is $0.22 \mathrm{~m}$.

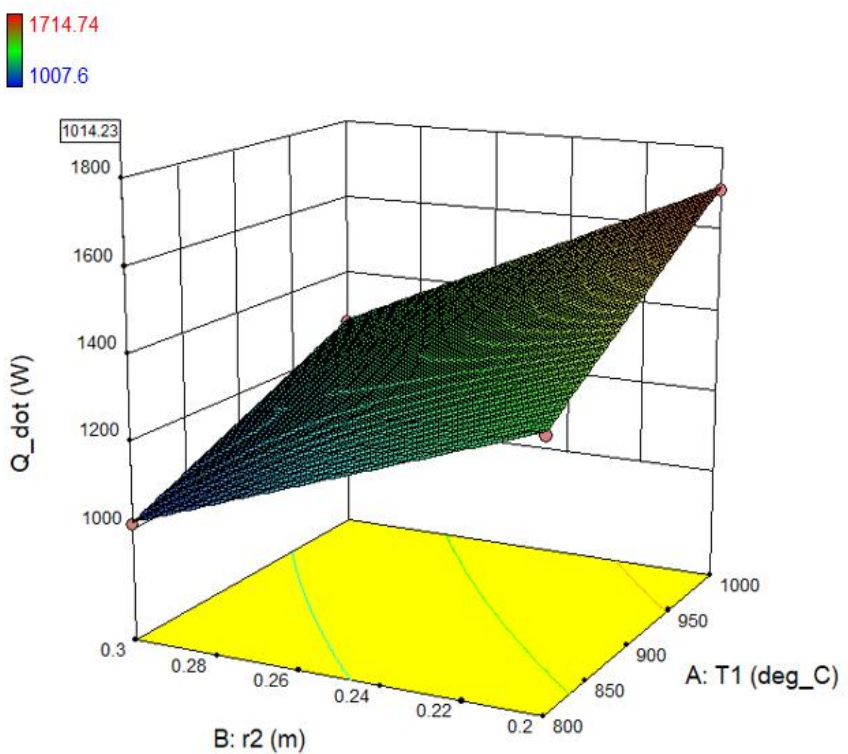

Figure 15: Optimal point after optimization

\section{CONCLUSION}

From the results obtained in this work, the following are the conclusions drawn from observation:

I. The ambient temperature had an insignificant effect on the rate of heat loss.

II. The most significant factor in both the axial and radial directions is the length of the thermal insulating material. The next is the temperature at the internal surface and lastly the interaction/combined effect of the length of the insulator and the temperature of the internal surface.

III. With all other factors kept constant, at $800{ }^{\circ} \mathrm{C}$, rate of heat loss is higher in the axial direction but at $1000{ }^{\circ} \mathrm{C}$ and all other factors held constant, the radial direction experiences higher rate of heat loss.

IV. From the simulation results, the length of $0.22 \mathrm{~m}$ will be used to construct a portable thermal storage unit within the operating temperature range of $700-900$ ${ }^{0} \mathrm{C}$.

V. The magnitude of effect in the axial direction is higher than that of the radial direction. This means higher sensitivity to change of any of the independent variables on the dependent variable in the axial direction. Might be due to different geometry of both direction.

FUNDING: This work was supported by the Covenant University Center for Research, Innovation and Discovery (CUCRID). 


\section{REFERENCES}

[1] M. Augspurger et al., Optimizing fin design for a PCMbased thermal storage device using dynamic Kriging, International Journal of Heat and Mass Transfer, 121 (2018) 290-308.

[2] A. Sciacovelli et al., Maximization of performance of a PCM latent heat storage system with innovative fins, Applied Energy, 137 (2015) 707-715.

[3] E. Kilickap, Modeling and optimization of burr height in drilling of Al-7075 using Taguchi method and response surface methodology, The International Journal of Advanced Manufacturing Technology, 49 (2010) (9-12) 911-923.

[4] C. Chen et al., Heat transfer performance and structural optimization design method of vertical phase change thermal energy storage device, Energy and Buildings, 68 (2014) 679-685.

[5] P. Bonadia et al., Refractory selection for long-distance molten-aluminium delivery, American Ceramic Society Bulletin, 85 (8) (2006) 9301-9309.

[6] G. Deshmukh et al., Thermal insulation materials: A tool for energy conservation, Journal of Food Processing \& Technology, 8 (4) (2017) 1-4.

[7] A. Ehsani, and I. Ehsani, Usage of vermiculite as a hightemperature insulating refractory material, Artıbilim: Adana Bilim ve Teknoloji Üniversitesi Fen Bilimleri Dergisi, 1 (2) (2018) 13-19.

[8] A. O. Ndubuisi et al., Estimation of optimal insulation thickness for a cylindrical ceramic crucible, International Journal of Engineering Research and Technology, 12 (9) (2019) 1389-1393.

[9] M. Fang, and G. Chen, Effects of different multiple PCMs on the performance of a latent thermal energy storage system, Applied Thermal Engineering, 27 (5-6) (2007) 994-1000.

[10] H. Michels, and R. Pitz-Paal, Cascaded latent heat storage for parabolic trough solar power plants, Solar Energy, 81 (6) (2007) 829-837.

[11] R. Alayil, and C. Balaji, Conjugate heat transfer in latent heat thermal storage system with cross plate fins, Journal of Heat Transfer, 137 (10) (2015) 102302.

[12] G. Zanganeh et al., Experimental and numerical investigation of combined sensible-latent heat for thermal energy storage at $575 \mathrm{C}$ and above, Solar Energy, 114 (2015) 77-90.

[13] L. Geissbühler et al., Analysis of industrial-scale hightemperature combined sensible/latent thermal energy storage, Applied Thermal Engineering, 101 (2016) 657668.

[14] T. Xie et al., Analysis of insulation performance of multilayer thermal insulation doped with phase change material, International Journal of Heat and Mass Transfer, 102 (2016) 934-943.
[15] A. Michot et al., Thermal conductivity and specific heat of kaolinite: Evolution with thermal treatment, Journal of the European Ceramic Society, 28 (14) (2008) 26392644.

[16] World Health Organization, Environmental Health Criteria 231. Bentonite, Kaolin, and Selected Clay Minerals, (2015) P-31.

[17] I. P. Okokpujie et al., Experimental and mathematical modeling for prediction of tool wear on the machining of aluminium 6061 alloy by high speed steel tools, Open Engineering, 7 (1) (2017) 461-469.

[18] I. P. Okokpujie et al., Modeling and optimization of surface roughness in end milling of aluminium using least square approximation method and response surface methodology, International Journal of Mechanical Engineering and Technology (IJMET), 9 (1) (2018) 587600. 